University of Wollongong

Research Online

Australian Institute for Innovative Materials -

Papers

Australian Institute for Innovative Materials

$1-1-2016$

\title{
Effects of carbon content on the electrochemical performances of MoS2-C nanocomposites for Li-lon batteries
}

\author{
Weiyi Sun \\ Nankai University \\ Zhe Hu \\ University of Wollongong, zh865@uowmail.edu.au \\ Caiyun Wang \\ University of Wollongong, caiyun@uow.edu.au \\ Zhanliang Tao \\ University of Wollongong, ztao@uow.edu.au \\ Shulei Chou \\ University of Wollongong, shulei@uow.edu.au
}

See next page for additional authors

Follow this and additional works at: https://ro.uow.edu.au/aiimpapers

Part of the Engineering Commons, and the Physical Sciences and Mathematics Commons

Research Online is the open access institutional repository for the University of Wollongong. For further information contact the UOW Library: research-pubs@uow.edu.au 


\title{
Effects of carbon content on the electrochemical performances of MoS2-C nanocomposites for Li-lon batteries
}

\author{
Abstract \\ Molybdenum disulfide is popular for rechargeable batteries, especially in Li-ion batteries, because of its \\ layered structure and relatively high specific capacity. In this paper, we report MoS2-C nanocomposites \\ that are synthesized by a hydrothermal process, and their use as anode material for Li-ion batteries. \\ Ascorbic acid is used as the carbon source, and the carbon contents can be tuned from $2.5 \mathrm{wt} \%$ to 16.2 \\ wt \%. With increasing of carbon content, the morphology of MoS2-C nanocomposites changes from \\ nanoflowers to nanospheres, and the particle size is decreased from 200 to $60 \mathrm{~nm}$. This change is caused \\ by the chemical complex interaction of ascorbic acid. The MoS2-C nanocomposite with $8.4 \mathrm{wt} \% \mathrm{C}$ \\ features a high capacity of 970 mAh g-1 and sustains a capacity retention ratio of nearly $100 \%$ after 100 \\ cycles. When the current increases to $1000 \mathrm{~mA} \mathrm{~g}-1$, the capacity still reaches $730 \mathrm{mAh}$ g-1. The above \\ manifests that the carbon coating layer does not only accelerate the charge transfer kinetics to supply \\ quick discharging and charging, but also hold the integrity of the electrode materials as evidenced by the \\ long cycling stability. Therefore, MoS2-based nanocomposites could be used as commercial anode \\ materials in Li-ion batteries.

\section{Disciplines} \\ Engineering | Physical Sciences and Mathematics

\section{Publication Details} \\ Sun, W., Hu, Z., Wang, C., Tao, Z., Chou, S., Kang, Y. \& Liu, H. (2016). Effects of carbon content on the \\ electrochemical performances of MoS2-C nanocomposites for Li-lon batteries. ACS Applied Materials \\ and Interfaces, 8 (34), 22168-22174.

\section{Authors} \\ Weiyi Sun, Zhe Hu, Caiyun Wang, Zhanliang Tao, Shulei Chou, Yong-Mook Kang, and Hua-Kun Liu
}




\title{
PEDOT doped with Algal, Mammalian and Synthetic Dopants: Polymer Properties, Protein and Cell Interactions, and Influence of Electrical Stimulation on Neuronal Cell Differentiation
}

\author{
P. J. Molino, ${ }^{a, b^{*}}$ L. Garcia, ${ }^{a}$ E.M. Stewart ${ }^{a}$, M. Lamaze, ${ }^{a}$ B. Zhang, ${ }^{a, c}$ A. Harris, ${ }^{a, c}$ P. Winberg, ${ }^{d}$ \\ G.G. Wallace ${ }^{a^{*}}$
}

${ }^{a}$ ARC Centre of Excellence for Electromaterials Science (ACES) and ${ }^{b}$ ARC Research Hub for Australian Steel Manufacturing, Intelligent Polymer Research Institute, University of Wollongong, Wollongong, NSW, 2522, Australia

'HEARing CRC, Intelligent Polymer Research Institute, University of Wollongong, Wollongong, NSW, 2522, Australia

dVenus Shell Systems Pty. Ltd, 220 Bolong Rd, Bomaderry, NSW, 2541

Corresponding author email: PJM (pmolino@uow.edu.au); GGW (gwallace@uow.edu.au)

\begin{abstract}
Poly(3,4-ethylenedioxythiophene) (PEDOT) films were electrochemically polymerised with several synthetic (dodecylbenzosulfonic acid (DBSA)) and biological (dextran sulphate (DS), chondroitin sulphate (CS), alginic acid (ALG) and ulvan (ULV)) dopant anions, and their physical, mechanical and electrochemical properties characterised. PEDOT films incorporating the biological dopants ALG and ULV produced films of the greatest surface roughness (46 \pm 5.1 and $31 \pm 1.9 \mathrm{~nm}$, respectively), and demonstrated significantly lower shear modulus values relative to all other PEDOT films $(2.1 \pm 0.1$ and $1.2 \pm 0.2 \mathrm{MPa}$, respectively). Quartz crystal microgravimetry was used to study the adsorption of the important extracellular matrix protein fibronectin, revealing protein adsorption to be greatest on PEDOT doped with DS, followed by DBSA, ULV, CS and ALG. Electrical stimulation experiments applying a pulsed current using a biphasic waveform $(250 \mathrm{~Hz})$ were undertaken using PEDOT doped with either DBSA or ULV. Electrical stimulation had a significant influence on cell morphology and cell differentiation for PEDOT films with
\end{abstract}


either dopant incorporated, with the degree of branching per cell increased by $10.5 \mathrm{x}$ on PEDOT-DBSA and $6.5 \times$ on PEDOT-ULV relative to unstimulated cells, and mean neurite length per cell increasing $2.6 \mathrm{x}$ and $2.2 \mathrm{x}$ on stimulated vs unstimulated PEDOT-DBSA and PEDOT-ULV, respectively. We demonstrate the cytocompatibility of synthetic and biologically doped PEDOT biomaterials, including the new algal derived polysaccharide dopant ulvan, which, along with DBSA doped PEDOT, are shown to significantly enhance the differentiation of PC12 neuronal cells under electrical stimulation.

\section{Introduction}

Organic conducting polymers (OCPs) have provided enormous scope for use in the biomaterials and tissue engineering fields due to the ability to tailor their physicochemical properties, and to exploit the unique combination of conductivity and electroactivity to provide a range of stimuli to excitable cells and tissues. For example, OCPs have been used for on-demand drug delivery of anti-inflammatory and anti-epileptic compounds ${ }^{1,2}$, the mechanical stimulation of cells ${ }^{3}$, and the direct electrical stimulation of cells and tissues in order to promote advantageous biological processes or cell behaviours ${ }^{4-6}$. OCPs are additionally amenable to a range of fabrication methodologies, providing researchers with opportunities to further exploit the materials through generating intricate biologically relevant architectures that allow us to address the nano-, micro- and macrobiological environment in a co-ordinated manner using such techniques as 3D printing, electrospinning, wet-spinning and extrusion printing ${ }^{7,8}$.

Poly(3,4-ethylenedioxythiophene) (PEDOT) is one OCP that has been shown to have properties that render their use in biological applications most appropriate ${ }^{9-13}$. However, there remains potential for the biocompatibility of OCPs to be increased in line with the complexity of natural biological films that include a multitude of functional molecules of different types. The use of synthetic dopants such as polystyrene sulfonate and para-toluene sulphate has been seen to be the dopants of choice from a physical properties point of view ${ }^{13-15}$. However to enhance the biocompatibility of OCPs the introduction of biological compounds as the anionic dopant during polymerisation ${ }^{12,16-18}$ 
has also been highly effective. The use of biological dopants not only enhances specific biointerfacing at the polymer surface, but also impacts on important bulk polymer properties such as hydration, porosity and modulus ${ }^{12,17}$. Both the composition of the biological dopant, and the degree of loading of the dopant into the polymer matrix, have been shown to affect a range of polymer physicochemical, mechanical and

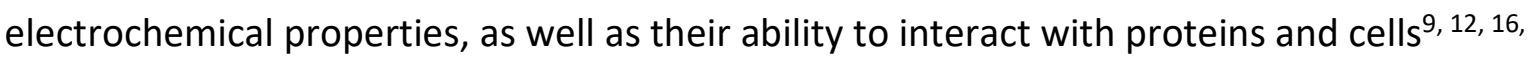
17.

Here we investigate the use of a range of synthetic and biological dopants on PEDOT polymer physicochemical, mechanical and electrochemical properties, and study their ability to interface with proteins and PC-12 neural cells. These dopants include chondroitin sulphate, which is a sulphonated glucosaminoglycan that is found in the extracellular matrix and has been demonstrated to contribute to protein binding and antiinflammatory processes ${ }^{19,20}$. Dextran sulphate is a bioactive polyanion that has been used as an antiviral agent and anticoagulant ${ }^{21,22}$, while alginate is a polysaccharide derived from brown algae that is widely investigated as a synthetic extracellular matrix material for biomedical applications ${ }^{23}$. Dodecylbenzosulfonic acid (DBSA) is a highly sulfonated synthetic compound that, when used the dopant species during conducting polymer synthesis, has been shown to produce polymers of good cytocompatibility ${ }^{18}$. In addition, we study the use of a dopant not yet exploited with OCPs; ulvan, a large molecular weight polysaccharide derived from the green alga genera Ulva. Ulvan is of interest to researchers as it has been shown to have a similar biochemistry to heparin, exhibiting anticoagulant ${ }^{24}$ and antibacterial ${ }^{25}$ properties, as well as demonstrating cytocompatibility with 7F2 osteoblast cells ${ }^{26}$. We compare the use of ulvan and dodecylbenzosulfonic acid as dopants to support the differentiation of PC12 cells under electrical stimulation conditions.

\section{Materials and Methods}

\subsection{Physical and Electrochemical Characterization of Polymer Film}

\subsubsection{Electrochemical Polymerization of PEDOT Polymer Films}


For Quartz Crystal Microbalance (QCM) studies, electrochemical polymerisation of EDOT was completed using a Q-Sense Electrochemistry Module (QEM 401) axial flow cell with a Q-Sense E4 Quartz Crystal Microbalance system (Q-Sense AB, Västra, Frölunda, Sweden) following previously published procedures ${ }^{12,16}$. Aqueous solutions of EDOT were prepared consisting of $0.01 \mathrm{M}$ EDOT in deionised water with $2 \mathrm{mg} \mathrm{mL}^{-1}$ of either dodecylbenzenesulfonic acid (DBSA) (Sigma 289957), dextran sulphate (DS) (Sigma D6001), chondroitin sulphate (CS) (Sigma C9819) or alginate (ALG) (Sigma A0682), or 1 $\mathrm{mg} \mathrm{mL}^{-1}$ ulvan (ULV) (PhycoTrix ${ }^{\mathrm{TM}}$, an ulvan type polymer from an Australian sourced species of Ulvaceae (Chlorophyta), was provided by Venus Shell Systems Pty Ltd (MW 1100,000). Each solution was de-oxygenated with nitrogen gas for $10 \mathrm{~min}$. The PEDOT films were grown galvanostatically onto gold coated Q-sense quartz sensors using an eDAQ 466 potentiostat. The aqueous polymer solution was passed through the QEM 401 axial flow cell at a rate of $60 \mu \mathrm{L} \mathrm{min}{ }^{-1}$ while a current density of $0.25 \mathrm{~mA} \mathrm{~cm}^{-2}$ was applied for $2 \mathrm{~min}$ for each film growth $\left(0.03 \mathrm{C} \mathrm{cm}^{-2}\right)$. Following electropolymerisation the quartz electrodes supporting the PEDOT films were removed from the cell, rinsed with deionised water and dried with nitrogen gas.

For cyclic voltammetry (CV) and cell culture studies, PEDOT films were polymerised on gold coated mylar (Solutia performance films, USA). EDOT - monomer aqueous solutions were prepared as above, and the films grown galvanostatically at a current density of $0.25 \mathrm{~mA} \mathrm{~cm}^{-2}$ for two minutes. The polymerisation took place in a three electrode electrochemical cell, consisting of a platinum mesh counter electrode, $\mathrm{Ag} \mid \mathrm{AgCl}$ reference electrode, and the gold mylar as the working electrode upon which the PEDOT film was polymerised. Following electropolymerisation the gold mylar supporting the PEDOT films were removed from the cell, rinsed with deionised water and dried with nitrogen gas.

\subsubsection{Cyclic Voltammetry}

Polymer films grown on gold mylar were placed in an electrochemical cell containing a platinum mesh counter electrode, $\mathrm{Ag} \mid \mathrm{AgCl}$ reference electrode, and the PEDOT film on gold mylar as the working electrode. Cyclic voltammograms (CVs) were performed in either (a) a $5 \mathrm{mM}$ Ferricyanide, $1 \mathrm{mM} \mathrm{NaCl}$ electrolyte solution, or (b) a DMEM solution, over a potential range of -0.6 to $+0.8 \mathrm{~V}$ at a scan rate of $100 \mathrm{mV} \mathrm{s}^{-1}$. An 
eDAQ e-corder 410 recorder and EA163 potentiostat were employed for all measurements.

\subsection{Atomic Force Microscopy}

The polymer film surfaces were imaged using an MFP-3D atomic force microscope (AFM) (Asylum Research, CA) with a Mikromash NSC15 cantilever (spring constant $\approx 37$ $\left.\mathrm{Nm}^{-1}\right)$. Images of the polymer surfaces were obtained using AC mode $(5 \mu \mathrm{m} \times 5 \mu \mathrm{m})$ at a $0.5 \mathrm{~Hz}$ scan rate in air. The Asylum Research Analysis software with the Igor Pro Software Package (WaveMetrics, OR) was used to determine the RMS roughness and surface area values.

\subsection{Goniometry}

The mean static contact angle measurements were performed using a DataPhysics optical contact angle goniometer. At least three measurements were undertaken on three separate films using deionised water droplets of $2 \mu \mathrm{L}$ for each reported value.

\subsection{Quartz Crystal Microbalance with Dissipation Monitoring (QCM-D) Modelling of Polymer Shear Modulus, Thickness and Mass}

Polymerisation of polymer films in-situ using QCM-D enabled the detailed analyses of the physical and mechanical properties of the polymer films. The Q-tools software package v.3.0.10.286 (Biolin Sci, AB) was used to apply the Voigt model using the QCM-D frequency and dissipation parameters to determine layer shear modulus, mass and thickness, using specific input parameters that provided the best data fit for the layer density $\left(1500 \mathrm{~kg} \mathrm{~m}^{-3}\right)$, fluid density $\left(1020 \mathrm{~kg} \mathrm{~m}^{-3}\right)$, layer viscosity $\left(0.0001 \leq 20 \mathrm{~kg} \mathrm{~ms}^{-1}\right)$, layer shear modulus (10 $\left.000 \leq 1 \times 10^{10} \mathrm{~Pa}\right)$, and layer thickness $\left(1 \times 10^{-9} \leq 1 \times 10^{-6} \mathrm{~m}\right)$. The $3^{\text {rd }}, 5^{\text {th }}$ and $7^{\text {th }}$ overtones were employed for all modelling calculations.

\subsection{Protein and Cell Interactions with PEDOT Films}

\subsubsection{Protein Adsorption Studies}


Protein adsorption experiments were carried out using a Q-Sense E4 Quartz Crystal Microbalance system (Q-Sense AB, Västra, Frölunda, Sweden). QCM sensor electrodes with the polymerised PEDOT films were transferred to a standard Q-Sense flow module (QFM 401) and equilibrated in PBS until stable frequency and dissipation values were established. All experiments were carried out at $22 \pm 0.02{ }^{\circ} \mathrm{C}$. Following equilibration a $50 \mu \mathrm{g} \mathrm{mL}^{-1}$ solution of fibronectin (FN) in PBS at physiological pH (7.4) was introduced into the axial flow module at a flow rate of $10 \mu \mathrm{L} \mathrm{min}{ }^{-1}$ for $60 \mathrm{~min}$, and then rinsed with PBS at a rate of $10 \mu \mathrm{L} \mathrm{min}^{-1}$ for 40 mins or until the QCM measurement parameters stabilised. All experiments were run in triplicate.

The Q-Tools software package was used to apply the Voigt model to determine the mass $\left(\mathrm{ng} \mathrm{cm}^{-2}\right)$ of the viscoelastic protein adlayer. The model input parameters that provided the best data fit were $1150 \mathrm{~kg} \mathrm{~m}^{-3}$ (layer density), $1020 \mathrm{~kg} \mathrm{~m}^{-3}$ (fluid density), $1^{-6}$ $\leq 1^{-2} \mathrm{~kg} \mathrm{~ms}^{-1}$ (layer viscosity), $1^{4} \leq 1^{7} \mathrm{~Pa}$ (layer shear modulus), and $115 \leq 1.15^{5} \mathrm{ng} \mathrm{cm}^{-2}$ (mass). The $3^{\text {rd }}, 5^{\text {th }}$ and $7^{\text {th }}$ overtones were used for all modelling calculations.

\subsubsection{Cell Culture}

Neuronal PC-12 cells were cultured in proliferation media (DMEM with $10 \%(\mathrm{v} / \mathrm{v})$ horse serum and 5\% (v/v) foetal bovine serum (FBS)) (Life technologies, Australia) in an incubator at $37^{\circ} \mathrm{C}$ with a humidified $5 \% \mathrm{CO}_{2}$ environment. Cell maintenance was required once PC-12 cells reached a confluence level of $90 \%$, which occurred every 4-5 days. A halfvolume medium change was performed every 2-3 days when needed, prior to subculturing. Cells were used for experimental work between passages 20-30.

\subsubsection{Cell Proliferation and Differentiation Studies}

Cell proliferation studies were performed by sterilising $\varnothing 5 \mathrm{~mm}$ discs $(n=4)$ of each PEDOT-dopant combination (CS, DBSA, DS, ALG and ULV) and Au mylar with 70\% (w/v) ethanol and transferring them to sterile 96-well plates (Greiner Bio-One, Austria) to dry under sterile conditions. PC-12 cells were collected from culture via centrifugation at $1500 \mathrm{rpm}$, resuspended in proliferation media and seeded at a density of $5 \times 10^{4} \mathrm{cells} / \mathrm{cm}^{2}$ on four replicates per material, in addition to a tissue culture plastic (TCP) control using the plate surface. Experimental plates were placed into the incubator at $37^{\circ} \mathrm{C}$ with a humidified $5 \% \mathrm{CO}_{2}$ environment and samples were removed at $24 \mathrm{~h}, 48 \mathrm{~h}$ and $72 \mathrm{~h}$ time 
points. Thereafter a PicoGreen assay modified from Otto ${ }^{27}$ was used to determine cell proliferation rates on the sample materials. Briefly, the media was then removed from each sample well and 0.1\% Triton X-100 (v/v) (1:200) in PBS was added to lyse cells for 5 min, followed by a freeze-thaw cycle $\left(-80^{\circ} \mathrm{C}\right.$ - room temperature). DNA was collected to analyse cell growth rates by measuring the dsDNA content per well using a Quant-iT PicoGreen dsDNA assay reagent. $2 \times 10^{6}$ cells used for the standard curve were resuspended in Tris-EDTA (TE buffer) and $0.1 \%$ SDS/TE buffer and then diluted for the final standards.

To prepare the PicoGreen assay, frozen samples were thawed and $10 \mu \mathrm{L}$ of sample was placed into corresponding wells in a 96-well plate (Greiner Bio-One, Austria) containing $90 \mu \mathrm{L}$ of TE buffer. PicoGreen reagent (Life Technologies, Australia) was diluted (1:200) with TE buffer, added to each well and then covered with foil and incubated for 5 min. A FLUOstar Omega plate reader (BMG LABTECH, Germany) was used to measure fluorescence at excitation $485 \mathrm{~nm}$ and emission $520 \mathrm{~nm}$, with a gain of 1250 and 10 flashes per well.

A differentiation assay was performed to compare PC-12 differentiation on the various substrates. $\varnothing 5 \mathrm{~mm}$ discs $(\mathrm{n}=3$ ) of the five PEDOT combinations (CS, DBSA, DS, ALG and ULV) and Au mylar were sterilised as previously outlined. PC-12 cells were seeded in proliferation media at a density of $1.5 \times 10^{3}$ cells $/ \mathrm{cm}^{2}$ onto the materials, and TCP, and placed in an incubator at $37^{\circ} \mathrm{C}$ with a humidified $5 \% \mathrm{CO}_{2}$ environment for $24 \mathrm{~h}$. Thereafter the proliferation media was then removed and replaced with differentiation media (DMEM (Life technologies, Australia) supplemented with $1 \%$ horse serum (v/v) and 0.05 $\mathrm{ng} / \mathrm{mL}$ nerve growth factor (NGF) (Promega, Australia)). The media was changed on the third day and samples were allowed to differentiate for 5 days prior to collection.

\subsubsection{Electrical Stimulation Studies}

Electrical stimulation studies of PC-12 cells on PEDOT films were performed following previously published methods ${ }^{4}$. Sterile PEDOT films ( $n=4$ for each material) were secured on 2-well chambers and incubated in DMEM overnight, and thereafter the media was removed and replaced with $20 \mathrm{mg} / \mathrm{mL}$ laminin in PBS and incubated at $4^{\circ} \mathrm{C}$ overnight. PC-12 cells were then seeded in proliferation media at a density of $1.5 \times 10^{3}$ 
cells $\mathrm{cm}^{-2}$ onto all surfaces. Cells were allowed to adhere for $24 \mathrm{~h}$ before the media was changed to differentiation media, at which time lids with fitted electrodes were employed. Before use, lid electrodes were initially soaked in isopropyl alcohol and then DMEM overnight, before being sterilised in $70 \%(\mathrm{w} / \mathrm{v})$ ethanol for $10 \mathrm{~min}$ and left to dry. PC-12 cells were placed under stimulated conditions for $8 \mathrm{~h}$ per $24 \mathrm{~h}$ period for 3 consecutive days in an incubator at $37^{\circ} \mathrm{C}$ with a humidified $5 \% \mathrm{CO}_{2}$ environment. A half media change of the differentiation media was performed on day 2 .

A schematic of the electrical stimulation model with cultured PC-12 cells on doped PEDOT is illustrated in Figure 1. Cells were stimulated at $\pm 0.25 \mathrm{~mA} \mathrm{~cm}^{-2}$ using a biphasic waveform of $100 \mu$ s pulses $(250 \mathrm{~Hz})$ with Digital Stimulator DS8000 and A365 Isolator units (World Precision Instruments, USA) and an e-corder system (eDAQ, USA) to record output. The voltage waveform across the active electrode area in response to the current pulse applied was recorded.

a.

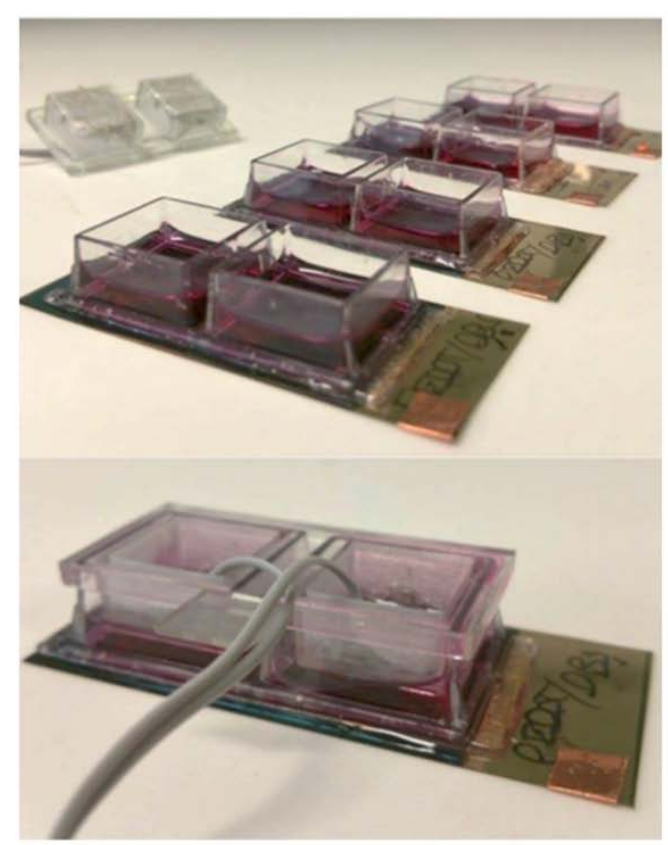

b.

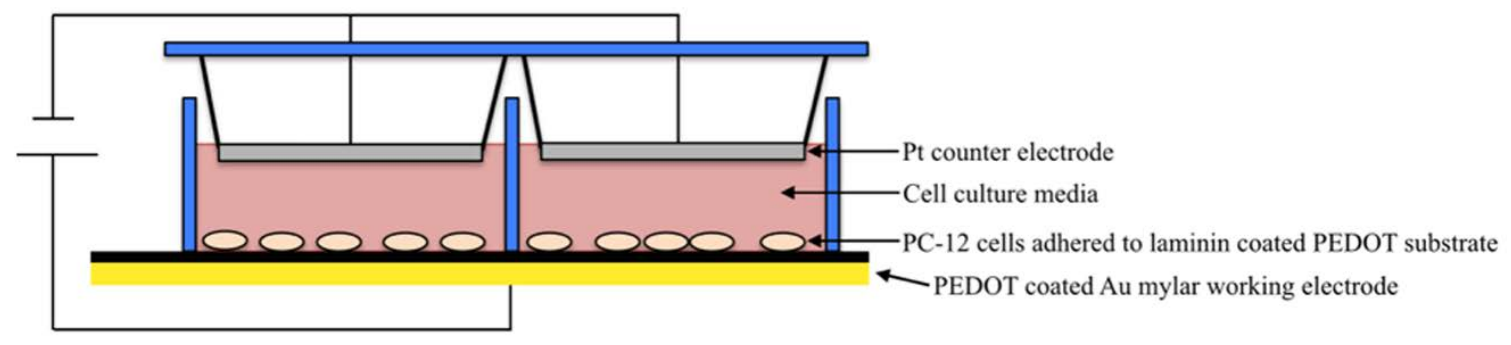


Fig 1. A scheme of the electrical stimulation model with cultured PC-12 cells on doped PEDOT. a. Photographs of custom cell culture stimulation model showing the Pt mesh counter electrode and cell culture chamber. b. A schematic of cell culture and electrical stimulation of PC-12 cells, including Pt counter electrode and PEDOT coated Au mylar working electrode.

\subsubsection{Fluorescence Staining and Imaging}

Cells were fixed with 3.7\% (w/v) paraformaldehyde (Fluka, Australia) in PBS for 10 min at room temperature and washed twice with PBS for $5 \mathrm{~min}$. Cells were then blocked and permeabilised for $1 \mathrm{~h}$ at $37^{\circ} \mathrm{C}$ in blocking buffer [10\% (v/v) donkey serum (Millipore, Australia) and $0.3 \%(\mathrm{v} / \mathrm{v})$ Triton X-100 in 1x PBS]. Primary antibodies, including mouse anti- $\beta$ III tubulin (Jomar Life Research, Australia) and rabbit anti-growth associated protein 43 (Gap43) (Millipore, Australia), were diluted (1:1000) in blocking buffer and incubated overnight at $4^{\circ} \mathrm{C}$. Cells were gently washed with wash buffer (1x PBS with $0.1 \%(v / v)$ Triton X-100) three times for $5 \mathrm{~min}$, before the addition of secondary antibodies, (Life Technologies, Australia) donkey anti-mouse Alexa Fluor 594 and donkey anti-rabbit Alexa Fluor 488 diluted (1:1000) in blocking buffer. Samples were incubated at $37^{\circ} \mathrm{C}$ for $45 \mathrm{~min}$ protected from light. Cells were washed an additional three times for $5 \mathrm{~min}$ in wash buffer, before the addition of 4',6-diamidino-2-phenylindole (DAPI) (Life Technologies, Australia) at 1:1000 dilution in 1x PBS for a further 5 min incubation. The DAPI solution was replaced with PBS and samples were mounted prior to imaging. Samples were removed from wells and placed on glass slides and mounted on a glass slide with a coverslip. Fluorescence imaging was conducted using an Axiolmager fluorescent microscope with an AxioCAM MRM camera (10 x lens) and Axio-Vision 4 software (Zeiss, Germany). Image analysis was performed using MetaMorph version 7.8 software (Molecular Devices, USA) for neurite analysis. Fluorescent images were taken using the same exposure time to allow standard image analysis comparisons. Using MetaMorph, the same parameters were employed for all images and cells.

\section{Results}




\subsection{Physical Characterisation}

PEDOTs containing each of the dopants CS, DS, ALG, DBSA and ULV were prepared according to the experimental protocols described above. AFM imaging of the PEDOT films reveal all polymers present a nanostructured nodular morphology that is typical of electrochemically polymerised PEDOT ${ }^{10,12,28,29}$ (Figure 2 ). The surface roughness (RMS Roughness) was similar for all PEDOT films except PEDOT-ULV and PEDOT-ALG, which illustrated the highest surface RMS Roughness values ( $31 \pm 1.9$ and $46 \pm 5.1 \mathrm{~nm}$, respectively) (Table I), however the homogeneity of PEDOT-ULV was evidently much higher than for PEDOT-ALG which appeared to be the most heterogenous of all surfaces. QCM-D modelling of the polymer properties found PEDOT-DS and PEDOT-CS to exhibit the greatest thickness and mass, with PEDOT-ALG and PEDOT-ULV presenting the lowest shear modulus of all polymer films (Table I). The most hydrophobic polymer was PEDOTDBSA $\left(68.4 \pm 1^{\circ}\right)$, followed by PEDOT-CS $\left(43 \pm 1.4^{\circ}\right)$, PEDOT-ALG $(37.8 \pm 1.6)$, PEDOT-DS $\left(35.8 \pm 1.1^{\circ}\right)$ and PEDOT-ULV $\left(29.6 \pm 0.8^{\circ}\right)$. 


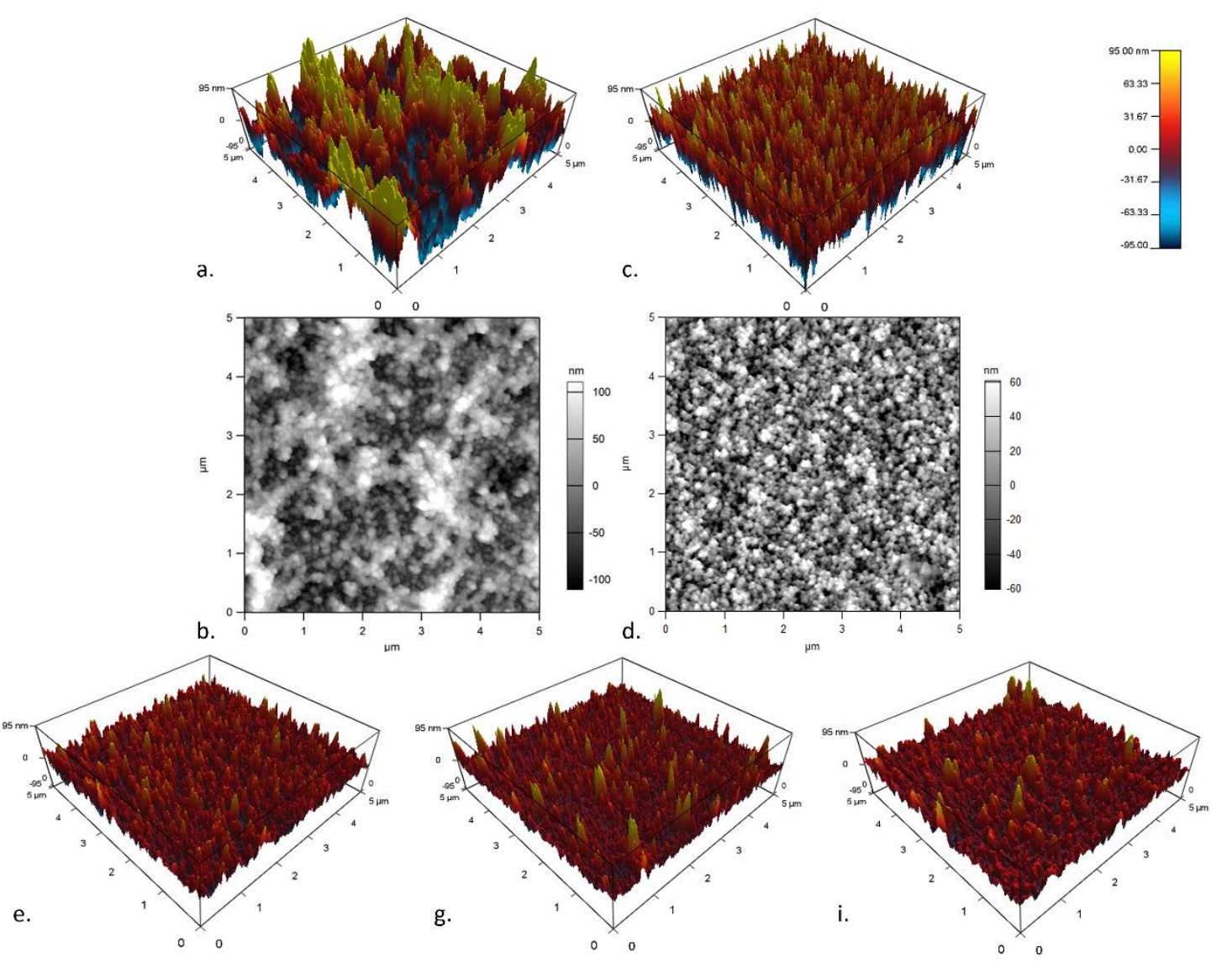

e.
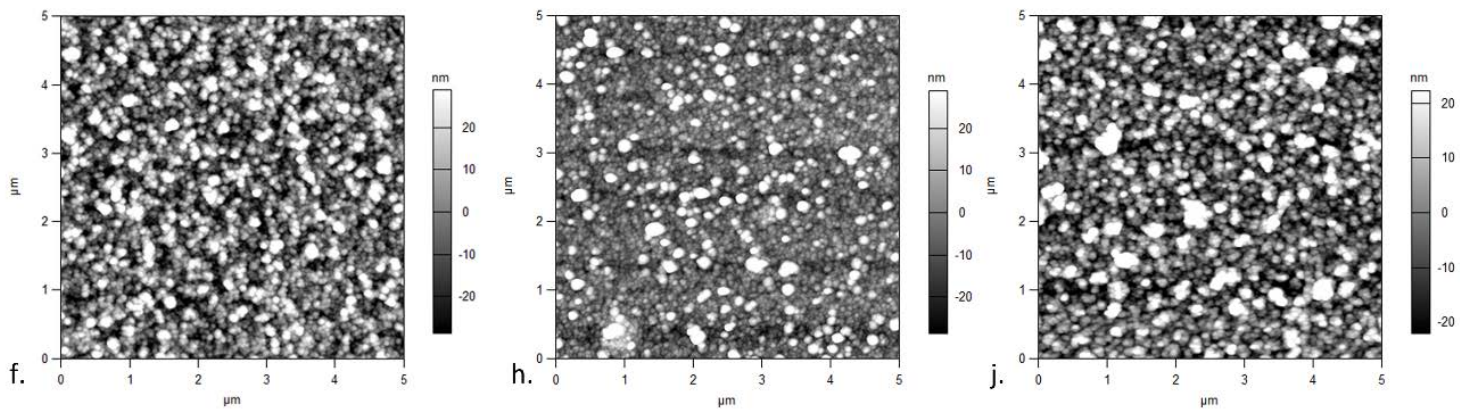

Fig 2. Representative $2 D$ and $3 D$ High Magnification $(5 \mu \mathrm{m} \times 5 \mu \mathrm{m})$ AFM images of PEDOT$\operatorname{ALG}(a, b)$, PEDOT-ULV (c,d), PEDOT-CS (e,f), PEDOT-DBSA (g,h) and PEDOT-DS $(\mathrm{l}, \mathrm{j})$. Colorcoded scale bars for both 2D and 3D images are to right of figure. 
Table I. Summary of physical and interfacial properties of PEDOT polymer films

\begin{tabular}{|c|c|c|c|c|c|c|}
\hline & & PEDOT-ALG & PEDOT-ULV & PEDOT-CS & PEDOT-DBSA & PEDOT-DS \\
\hline \multirow[b]{2}{*}{$\sum_{\substack{\longleftarrow \\
\leftarrow}}$} & $\mathrm{R}_{\mathrm{RMS}}$ roughness $(\mathrm{nm})$ & $46 \pm 5.1$ & $31 \pm 1.9$ & $16.4 \pm 2.3$ & $15.7 \pm 0.15$ & $15.9 \pm 0.51$ \\
\hline & $\begin{array}{l}\text { Increased Surface area } \\
\text { (\%) }\end{array}$ & $33.1 \pm 6$ & $51.1 \pm 2.4$ & $13.3 \pm 4.5$ & $15.6 \pm 3.6$ & $11.2 \pm 3.1$ \\
\hline \multirow{4}{*}{ 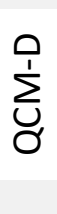 } & Thickness (nm) & $344 \pm 17.8$ & $329 \pm 70.8$ & $485 \pm 4$ & $237 \pm 2$ & $515 \pm 18$ \\
\hline & $\operatorname{Mass}\left(\mu \mathrm{g} \cdot \mathrm{cm}^{-2}\right)$ & $50 \pm 1$ & $54 \pm 1.3$ & $72.8 \pm 0.5$ & $35.5 \pm 0.3$ & $77.4 \pm 2.7$ \\
\hline & Shear Modulus (MPa) & $2.1 \pm 0.1$ & $1.2 \pm 0.2$ & $34.7 \pm 0.4$ & $127.9 \pm 38.0$ & $28.5 \pm 1.8$ \\
\hline & Static Contact angle $\left({ }^{\circ}\right)$ & $37.8 \pm 1.6$ & $29.6 \pm 0.8$ & $43 \pm 1.4$ & $68.4 \pm 1.0$ & $35.8 \pm 1.1$ \\
\hline
\end{tabular}

\subsection{Electrochemical Characterisation}

\subsubsection{Cyclic Voltammetry (CV)}

Voltammograms performed in DMEM, the media used for cell stimulation studies, displayed a large increase in current magnitude after coating the gold coated mylar with all doped PEDOT treatments (Figure 3a), although they were relatively lower for PEDOTALG compared to the other PEDOT treatments. III defined, small and broad reduction and

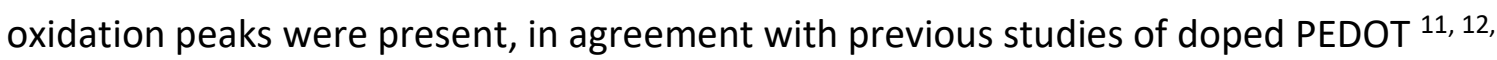
30, 31. Voltammograms were also performed in a $5 \mathrm{mM}$ Ferricyanide, $1 \mathrm{mM} \mathrm{NaCl}$ electrolyte solution and indicate charge transfer across the electrolyte-OCP interface is possible (Figure $3 \mathrm{~b}$ ). Therefore, all of the doped PEDOT films possess larger charge injection capacities than unmodified gold mylar. 


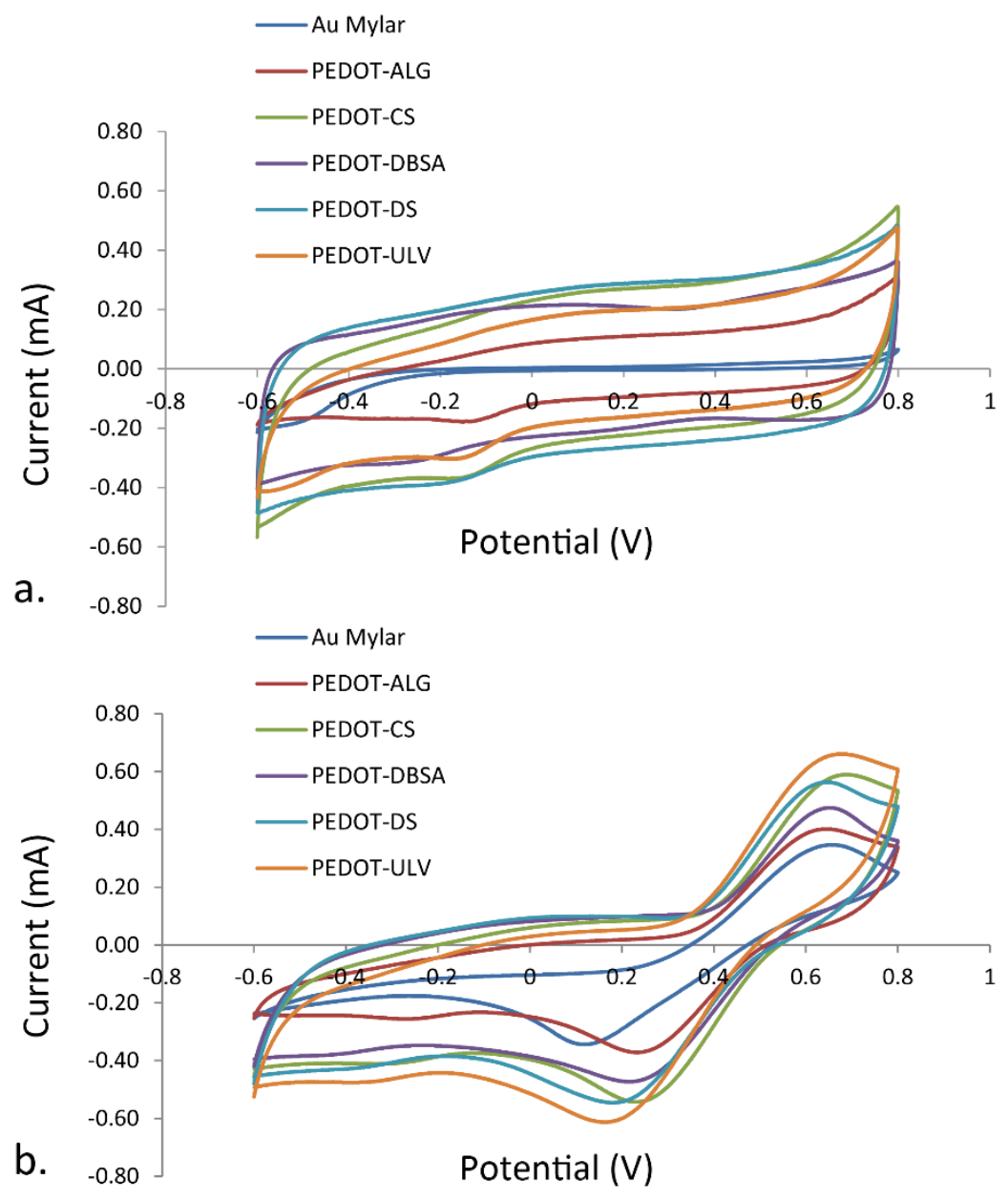

Fig 3. Cyclic voltammograms of Au mylar, PEDOT-ALG, PEDOT-CS, PEDOT-DBSA, PEDOTDS, and PEDOT-ULV. Measurements were performed in (a)DMEM solution and (b) $5 \mathrm{mM}$ Ferricyanide, $1 \mathrm{mM} \mathrm{NaCl}$ electrolyte solution, at a scan rate of $100 \mathrm{mVs}^{-1}$ over the potential range of -0.6 to $+0.8 \mathrm{~V}$. Five cycles were performed, and the $4^{\text {th }}$ cycle is presented.

\subsection{Biological Characterisation}

\subsubsection{Fibronectin Adsorption}

Fibronectin is an important extracellular matrix protein that is known to be critical in guiding cell-surface interactions, as well as interfacing with other extracellular matrix components such as collagen, proteoglycans and other cell adhesion molecules ${ }^{32}$, and therefore is an appropriate model protein to study material bio-interfacing. Figure 4 illustrates the modelled mass values, and the $\Delta D / \Delta f$ ratio, from the raw $Q C M-D$ parameter shifts from the adsorption of FN to the PEDOT films. Modelling of the QCM-D parameters reveals PEDOT-DS to present the greatest FN adsorption, followed by PEDOT- 
DBSA, PEDOT-ULV, PEDOT-CS and PEDOT-ALG (Figure 4a). The $\Delta D / \Delta f$ provides

information on the viscoelastic properties of the adsorbed protein layer, which can be correlated with the conformation of the adsorbed protein layer ${ }^{12,16}$. A large $\Delta D / \Delta f$ is indicative of a soft, more hydrated surface adlayer, while a lower value presents a more elastic, dehydrated layer. FN adsorbed to PEDOT-CS and PEDOT-ALG presents by far the most viscoelastic and hydrated protein layer with $\Delta D / \Delta f$ ratios of $0.16 \pm 0.016$ and $0.20 \pm$ 0.031, respectively, followed by PEDOT-DBSA (0.066 \pm 0.001$)$ and PEDOT-ULV $(0.066 \pm$ 0.027), and finally PEDOT-DS (0.051 \pm 0.000$)$ (Figure $4 b)$.

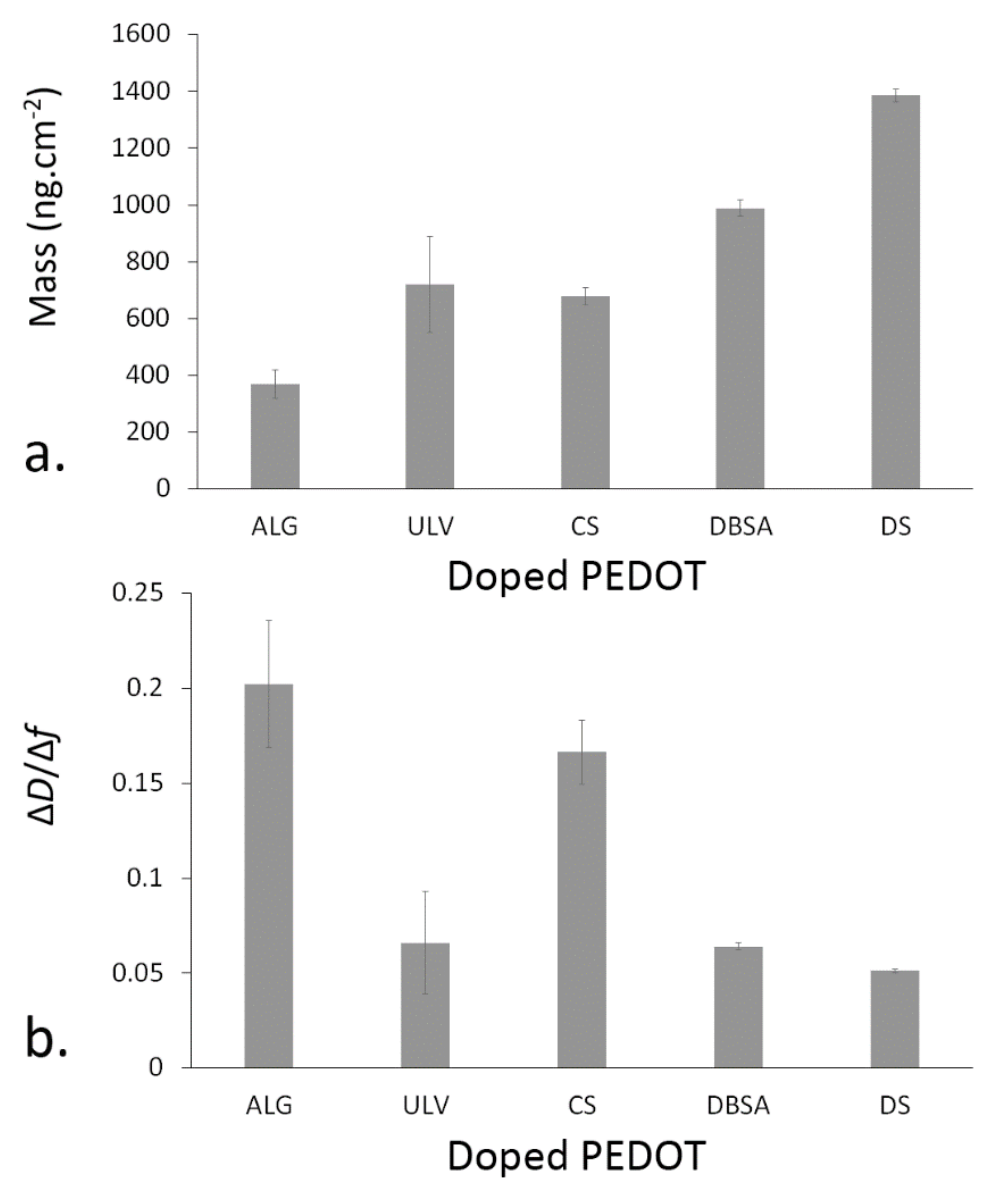

Fig 4. QCM-D modelling results for the adsorption of fibronectin to the PEDOT composite materials. (a) Average mass of fibronectin adsorbed to the PEDOT composite films, normalised against surface area. (b) $\Delta D / \Delta f$ data for the adsorption of fibronectin to the PEDOT composite films. All error bars represent $95 \% \mathrm{Cl}$ around the mean. 


\subsubsection{PC12 Proliferation and Differentiation}

There were no significant differences in cell number on samples at the $24 \mathrm{~h}$ time point of the cell proliferation assay $(p>0.05)$ (Figure 5). By $48 \mathrm{hrs}$ cell numbers on the TCP control and PEDOT-ALG increased significantly compared to all other materials except $\mathrm{Au}$ mylar and PEDOT-CS $(P<0.05)$. There were significant differences between samples at the $72 \mathrm{~h}$ time point, with cell numbers on TCP significantly higher compared to PEDOT-CS and PEDOT-DS, with mean cell numbers remaining constant or decreasing from $48 \mathrm{hrs}$ to $72 \mathrm{hrs}$ for all PEDOT polymers except PEDOT-ULV which demonstrated a mean increase and the highest cell number for all PEDOT films.

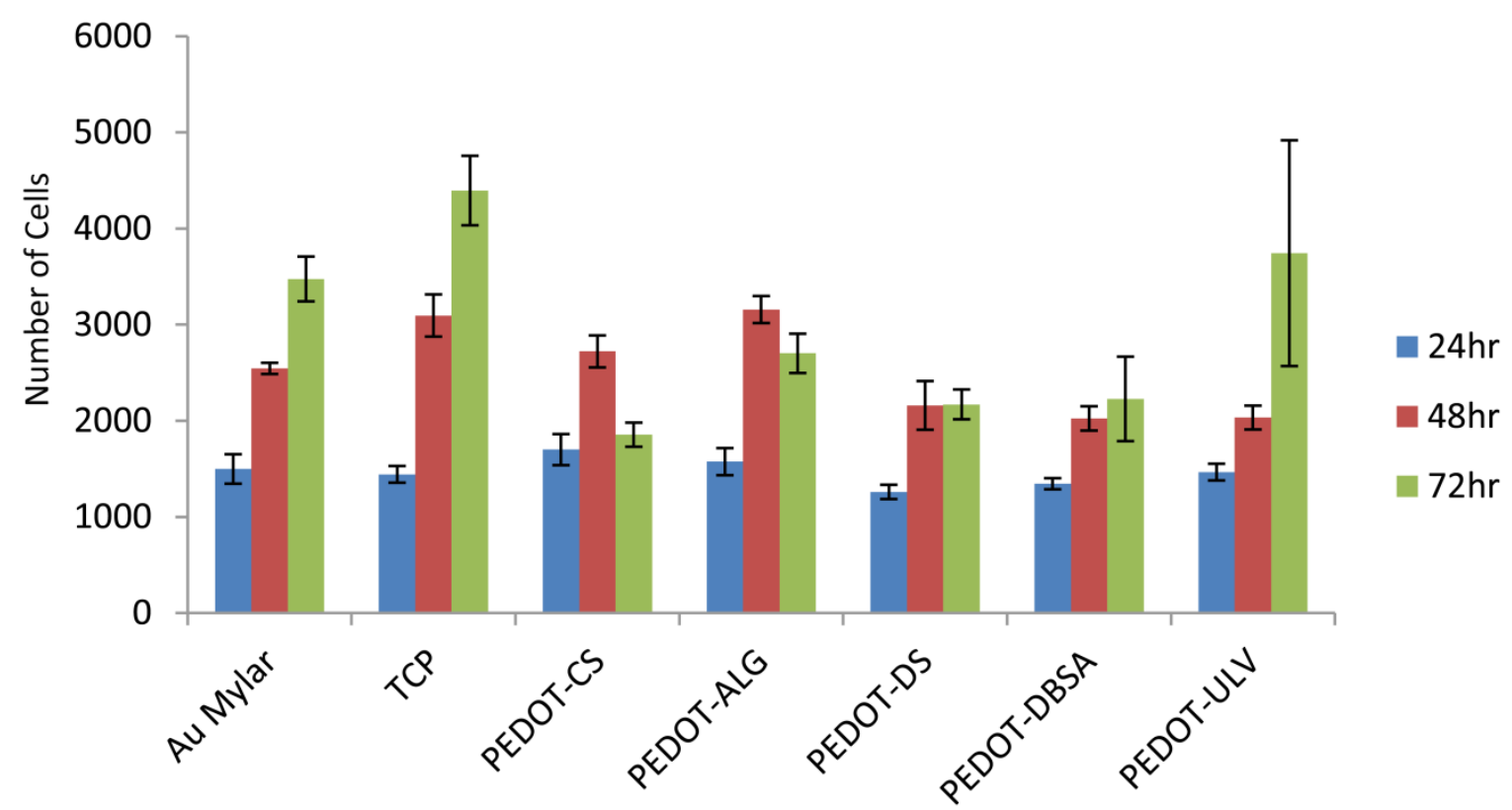

Fig 5. Proliferation of PC-12 cells on various PEDOT and control materials over $72 \mathrm{~h}$ including: PEDOT-ALG, PEDOT-CS, PEDOT-DBSA, PEDOT-DS, and PEDOT-ULV and control substrates Au mylar and TCP. Time points: $24 \mathrm{~h}$ (black), $48 \mathrm{~h}$ (red) and $72 \mathrm{~h}$ (blue). Mean \pm Standard error around the mean (SEM) $(n=4)$. Statistical analyses performed were a Oneway ANOVA and Bonferroni post hoc analysis.

PC-12 cells were maintained under differentiation culture conditions for 5 days on substrates and then immunostained with markers $\beta$ III tubulin (red) for neuron-specific cytoplasmic staining, DAPI (blue) for nuclear staining and GAP43 (green) for neural growth cone staining. All cells displayed positive staining for $\beta$ III tubulin indicating they are of neural phenotype, and significant outgrowth can be seen from a number of cells 
within each population (Figure 6). Cells with neurites expressed GAP43 on their extended processes, and no obvious differences in the expression levels or distribution were seen between materials.

Quantitative analysis of cell morphology was performed using MetaMorph to examine maximum neurite length per cell $(\mu \mathrm{m})$, mean neurite branching per cell, mean cell body area $\left(\mu \mathrm{m}^{2}\right)$, mean neurite length per cell $(\mu \mathrm{m})$ and mean number of neurites per cell (Figure 7). PEDOT-CS presented the highest average maximum neurite length/cell of all materials tested. There was little difference in the mean number of branches per cell between materials, and Au mylar illustrated the greatest mean cell body area of all materials, with TCP demonstrating the least. Au mylar also demonstrated the greatest number of neurites per cell, followed by PEDOT-DS, PEDOT-DBSA, PEDOT-ULV, PEDOT-CS and PEDOT-ALG. There was little difference in total outgrowth length per cell, with TCP illustrating the lowest total outgrowth length per cell of all materials. Comparing the percentage of differentiated vs undifferentiated cells on each substrate, Au mylar (control) supported the highest proportion of differentiated cells (51\%), followed by PEDOT-DBSA (49\%), PEDOT-DS (45\%), PEDOT-ALG (38\%), PEDOT-ULV (37\%), PEDOT-CS (29\%) and TCP (control) (16\%) respectively (Figure 8). 

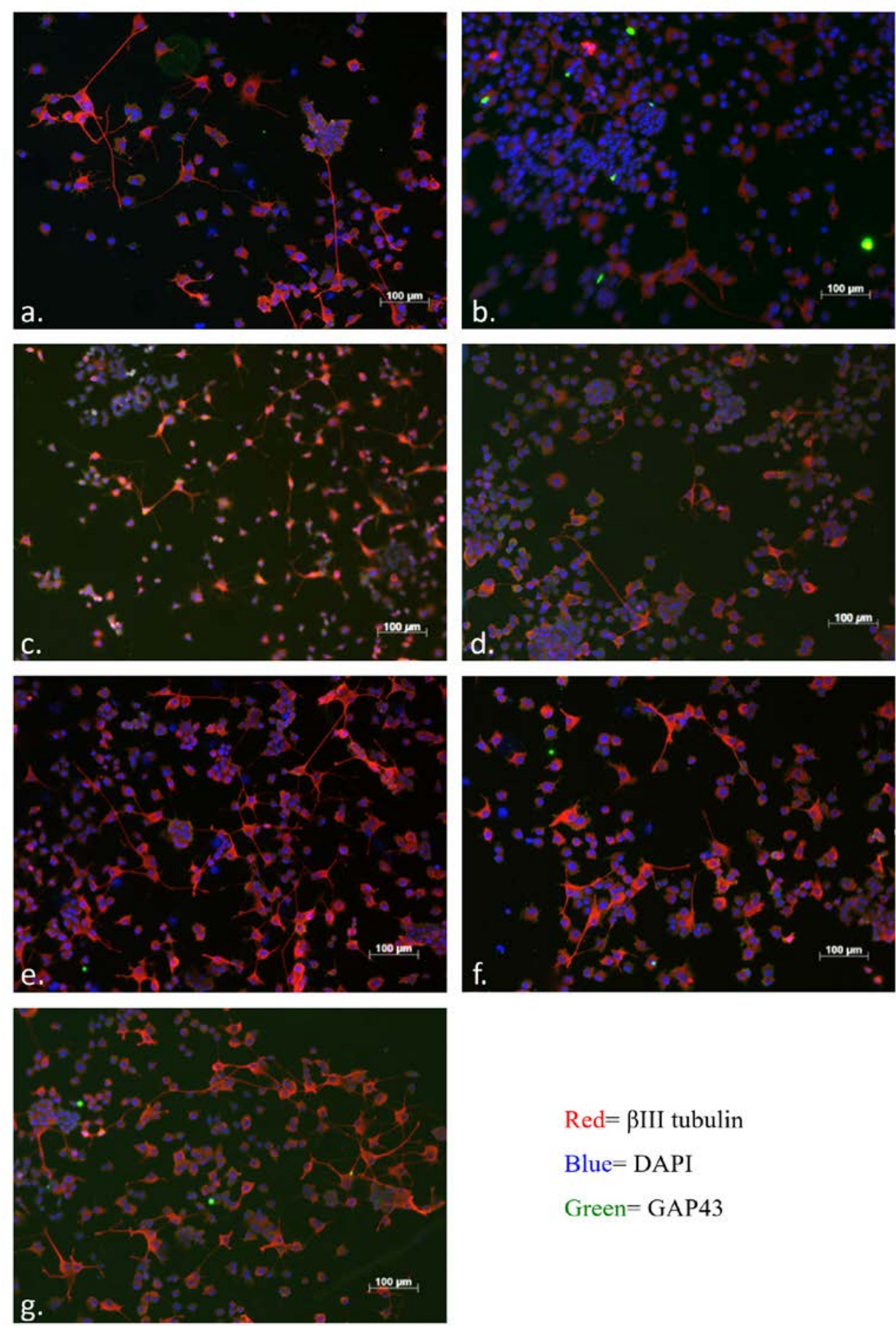

$$
\begin{aligned}
& \text { Red }=\beta \text { III tubulin } \\
& \text { Blue= DAPI } \\
& \text { Green= GAP43 }
\end{aligned}
$$

Fig 6. Immunocytochemical characterisation of PC-12 cells on PEDOT substrates following 5 days of cell differentiation (scale bar represents $100 \mu \mathrm{m}$ ). Substrates include: (a) Au mylar and (b) TCP controls, (c) PEDOT-ALG, (d) PEDOT-CS, (e) PEDOT-DBSA, (f) PEDOT-DS, (g) PEDOT-ULV. Immunostaining markers include: $\beta$ III tubulin (red) for neuron-specific cytoplasmic staining, DAPI (blue) for nuclear staining and GAP43 (green) for neural growth cone staining. 

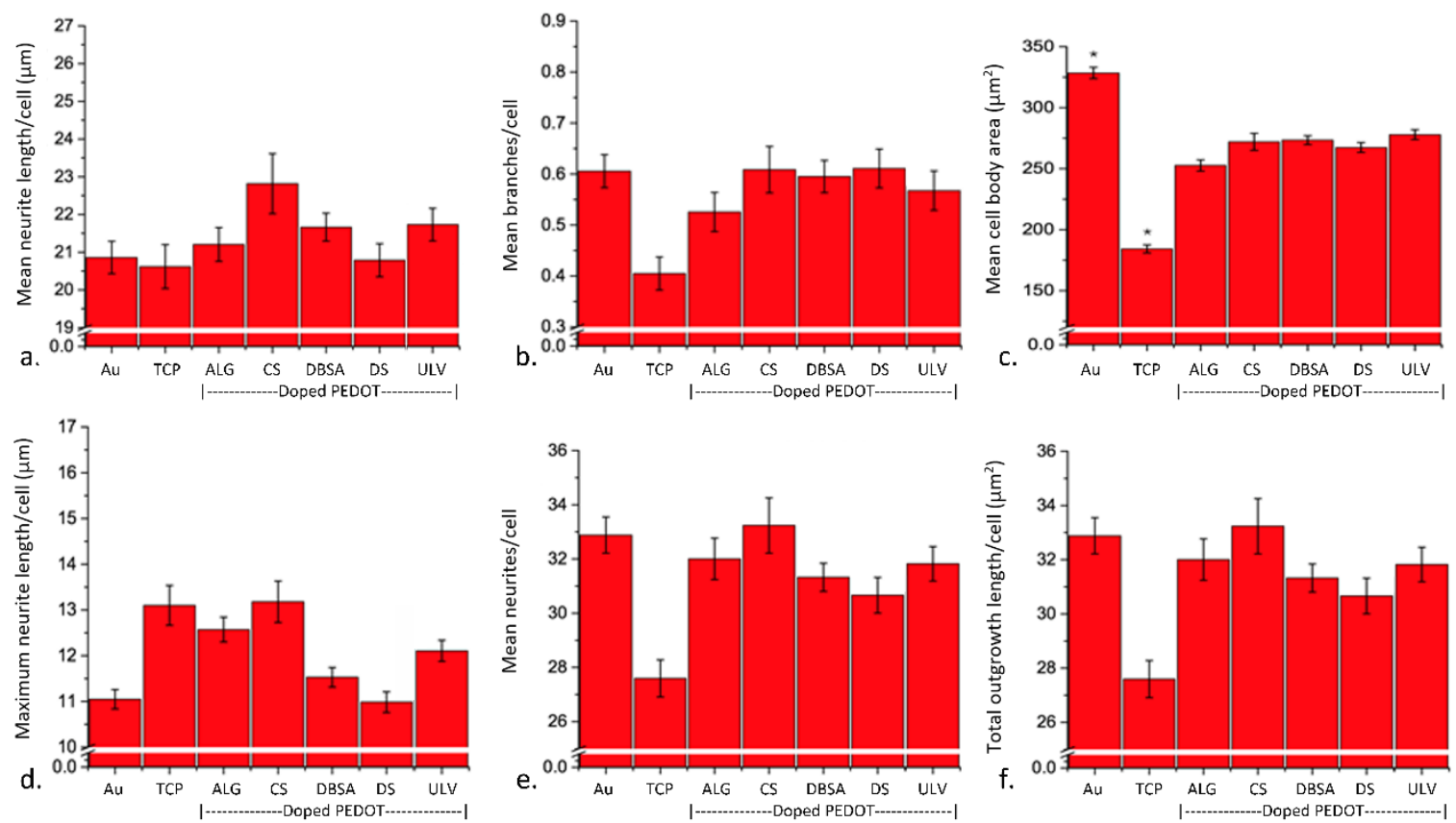

Fig 7. MetaMorph software (MetaMorph, USA) image analysis of PC-12 cell morphology after 5 days of cell differentiation. Substrates include: PEDOT-ALG, PEDOT-CS, PEDOTDBSA, PEDOT-DS, PEDOT-ULV and controls Au mylar and TCP. Parameters examined were as follows; (A) maximum neurite length per cell \pm SEM ( $n=$ approx. 2000), (B) mean neurite branches per cell \pm SEM ( $n=$ approx. 2000), (C) mean cell body area per cell \pm SEM ( $n=$ approx. 2000), (D) mean neurite length per cell \pm SEM ( $n=$ approx. 2000$),(E)$ mean number of neurites per cell \pm SEM ( $n=$ approx. 2000), and $(F)$ total outgrowth length per cell \pm SEM $(n=2000)$. Statistical analyses used were a One-way ANOVA and Bonferroni post hoc analysis. * represents significant difference between the indicated sample and all other samples $(p<0.05)$. 


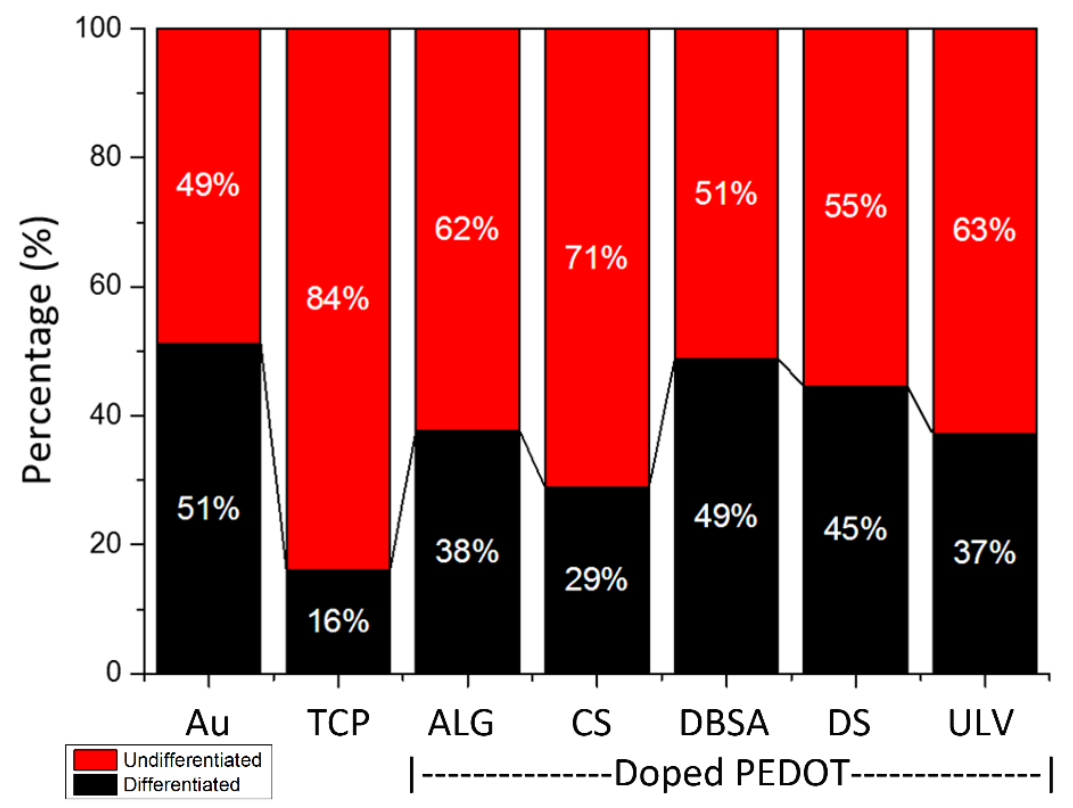

Fig 8. MetaMorph software (Molecular Devices, USA) image analysis of cell number and percentage of differentiated vs undifferentiated cells. Substrates include: PEDOT-ALG, PEDOT-CS, PEDOT-DBSA, PEDOT-DS, PEDOT-ULV and controls Au mylar and TCP. 


\subsection{Electrical Stimulation}

To observe the effect of electrical stimulation delivered through PEDOT-DBSA and PEDOT-ULV films on PC-12 cells, electrical stimulation methodology was followed in accordance with Richardson et al. ${ }^{33}$ and Stewart et al. ${ }^{4}$. Cells were placed under stimulated conditions for $8 \mathrm{~h}$ per $24 \mathrm{~h}$ period for 3 days in an incubator at $37^{\circ} \mathrm{C}$ with a humidified $5 \% \mathrm{CO}_{2}$ environment. The voltage output from each electrical stimulation cell was monitored for the duration of the electrical stimulation period. Importantly, for both DBSA and ULV doped PEDOT there was minimal change in the output voltage during the stimulation period (data not shown), indicating electrochemical stability of the films during cell stimulation.

Cells were immunostained with markers $\beta$ III tubulin (red) for neuron-specific cytoplasmic staining and DAPI (blue) for nuclear staining (Figure 10). Quantitative analysis of cell morphology revealed that for all parameters investigated except mean cell body area, the electrically stimulated PEDOT-DBSA and PEDOT-ULV polymers demonstrated significantly greater values than the non-stimulated and TCP control surfaces (Figure 11). The greatest differences were seen for the degree of branching per cell which was 10.6x greater on PEDOT-DBSA and 6.5x greater on PEDOT-ULV relative to the respective unstimulated films, with mean neurite length per cell $2.6 x$ and $2.2 x$ on stimulated vs unstimulated PEDOT-DBSA and PEDOT-ULV, respectively.

When comparing the degree of differentiation vs non-differentiated cell on each of the tested substrates, the highest rate of differentiation was seen on stimulated PEDOT-ULV (97\%), followed by stimulated PEDOT-DBSA (96\%), non-stimulated PEDOTULV (95\%), TCP (93\%) and non-stimulated PEDOT-DBSA (90\%) (Figure 11g). The overall proportion of differentiated cells were greater here than compared to the previous differentiation study on all materials due to the use of a laminin coating on all materials prior to cell seeding. 

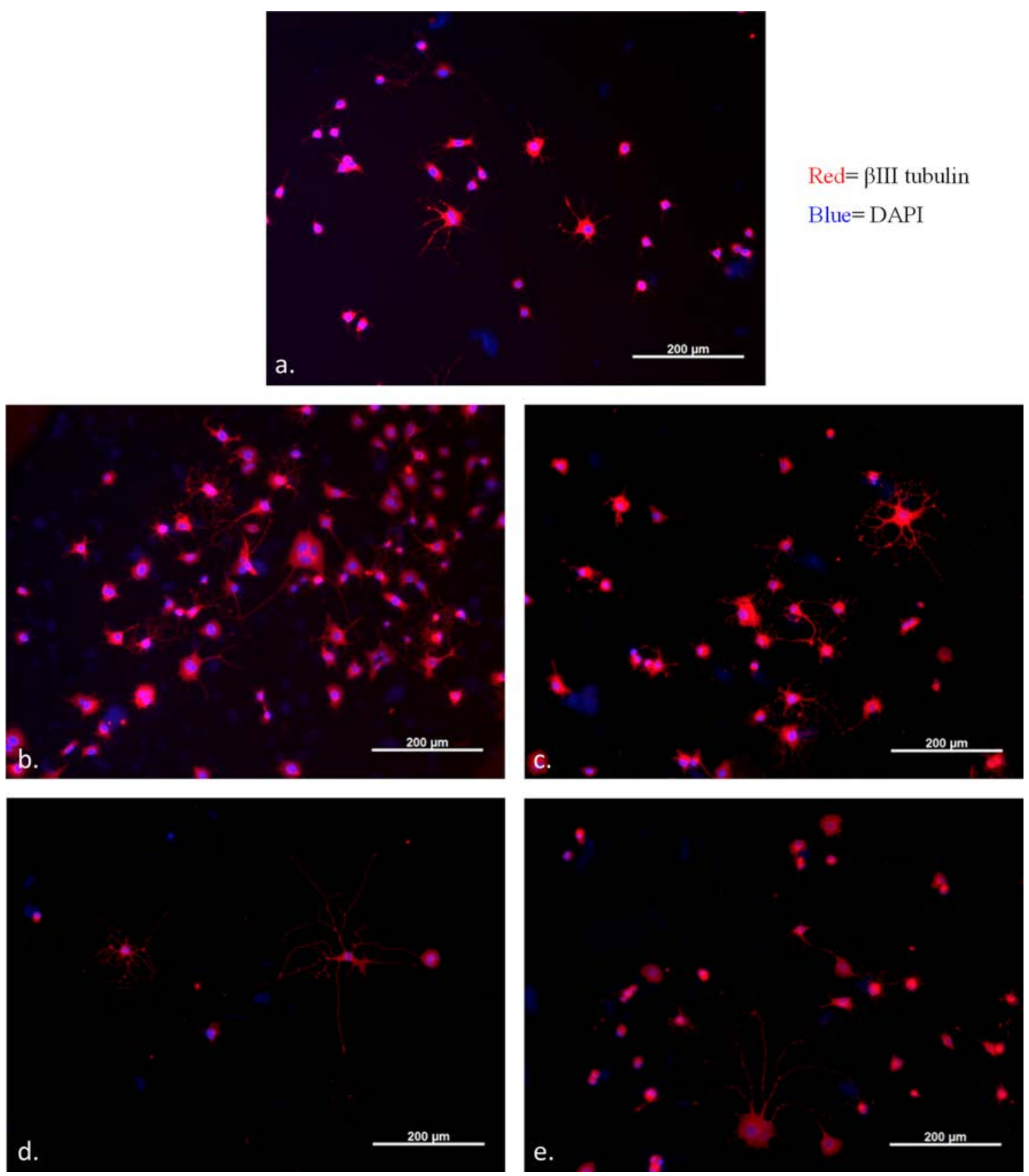

Fig 9. Immunocytochemical characterisation of PC-12 cells on stimulated and unstimulated PEDOT-DBSA and PEDOT-ULV substrates and TCP control (scale bar represents $100 \mu \mathrm{m}$ ). Cells were under stimulated conditions for $8 \mathrm{~h}$ per $24 \mathrm{~h}$ period for 3 days in an incubator at $37^{\circ} \mathrm{C}$ with a humidified $5 \% \mathrm{CO}_{2}$ environment. Substrates: (a) TCP control, (b) PEDOT-DBSA, (c) PEDOT-ULV, (d) Stimulated PEDOT-DBSA, (e) Stimulated PEDOT-ULV. Immunostaining markers: $\beta$ III tubulin (red) for neuron-specific cytoplasmic staining and DAPI (blue) for nuclear staining. 


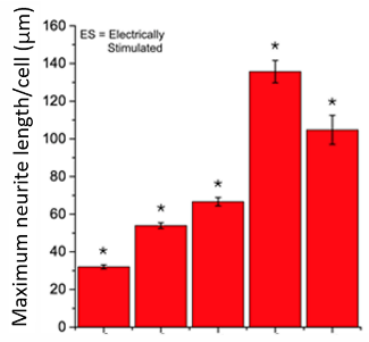

a. TCP DBSA ULV ES- ESDBSA ULV
|-----doped PEDOT-----|

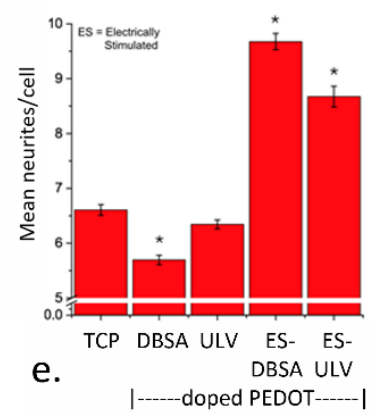

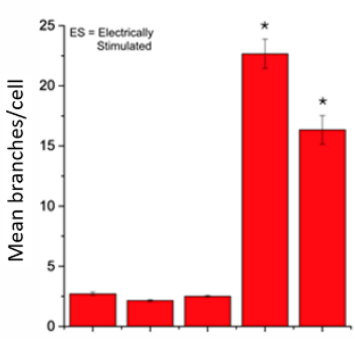

b. TCP DBSA ULV ES- ES-

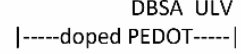

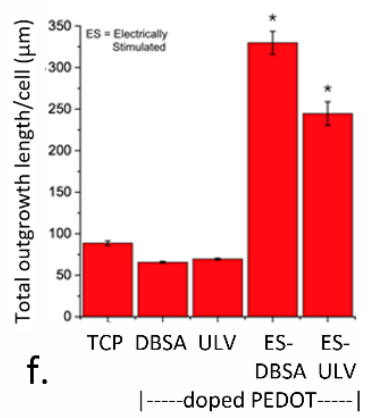

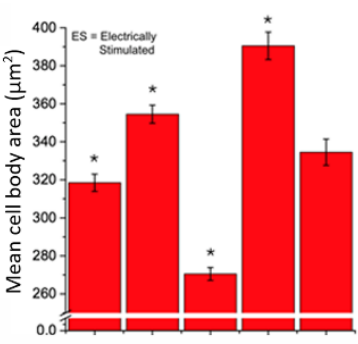

C. TCP DBSA ULV ES- ES|-----doped PEDOT-----|

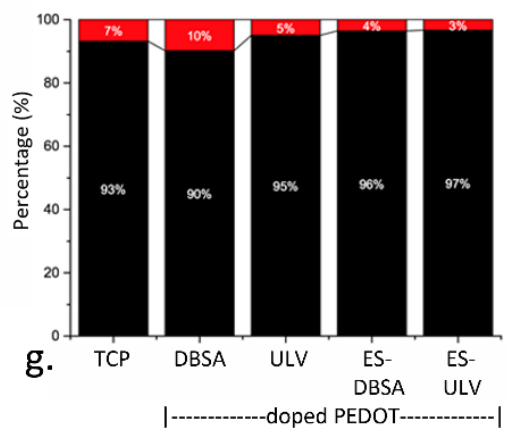

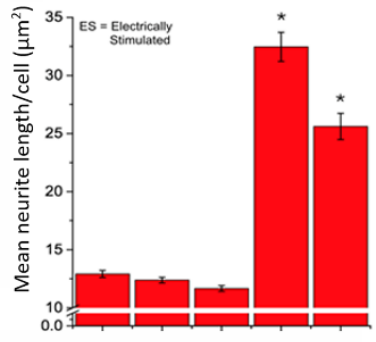

d. TCP DBSA ULV ES- ES|------doped PEDOT------|

Fig 10. MetaMorph software (Molecular Devices, USA) image analysis of the effect of electrical stimulation through PEDOT films to PC-12 cells. Cells were under stimulated conditions for $8 \mathrm{~h}$ per $24 \mathrm{~h}$ period for 3 days in an incubator at $37^{\circ} \mathrm{C}$ with a humidified $5 \% \mathrm{CO}_{2}$ environment. Controls: unstimulated PEDOT-DBSA and PEDOT-ULV, and TCP. Parameters examined were as follows; (a) maximum neurite length per cell \pm SEM ( $n=$ approx. 1000), (b) mean neurite branches per cell \pm SEM ( $n=$ approx. 1000), (c) mean cell body area per cell \pm SEM ( $n=$ approx. 1000), (d) mean neurite length per cell \pm SEM ( $n=$ approx. 1000), (e) mean number of neurites per cell \pm SEM ( $n=$ approx. 1000), and (f) total outgrowth length per cell \pm SEM ( $n=$ approx. 1000), (g) Percentage of differentiated vs undifferentiated cells. Statistical analyses used were a One-way ANOVA and Bonferroni post hoc analysis. * represents significant difference between the indicated sample and all others $(p<0.05)$.

\section{Discussion}

The incorporation of biodopants into conducting polymers has been widely studied as a facile and versatile method through which to enhance and/or tailor 
conducting polymer cytocompatibility and biointerfacing. Herein the doping of PEDOT with the algal derived large polysaccharide dopants ULV and ALG significantly reduced polymer shear modulus, and increased interfacial roughness, relative to other biological and synthetic dopants tested (Table I). Material interfacial properties, including roughness and wettability, guide the nature of protein interactions with biomaterials that mediate all subsequent biomolecular and cellular interactions at the material surface $^{34}$. QCM-D was used to study the nature of FN adsorption to all materials, with adsorption greatest on PEDOT-DS, PEDOT-DBSA, PEDOT-ULV and PEDOT-CS, with PEDOT-ALG demonstrating the least adsorption (Figure 4). The viscoelastic properties of the FN layer were greatest on the PEDOT-CS and PEDOT-ALG, which has previously been proposed to be illustrative of a more extended and open conformation that is more bioactive ${ }^{16}$, thus suggestive that, although not presenting the highest degree of binding, PEDOT-CS and PEDOT-ALG may present surface properties particularly beneficial to biointerfacing with $\mathrm{FN}$ and other extracellular matrix components. Interestingly the general surface properties of the polymers (i.e. wettability, roughness) did not provide an obvious relationship or correlation with protein binding, indicating the likelihood that the specific chemistries presented at the polymer interface play a greater role in guiding protein interactions than the general surface characteristics.

Furthermorehere was no clear correlation between material interfacial and mechanical properties and cell proliferation and differentiation, with all PEDOT films presenting a suitability as supporting substrates for cell proliferation compared to the controls, indicating their potential use as cell supportive scaffolds. Previous studies using biological dopants with PEDOT have shown the polymers to support PC-12 cells ${ }^{10}$, 12,35 and explanted spiral ganglion neurons ${ }^{36}$, with PPy-biodopant composites shown to support human osteoblast adhesion ${ }^{37}$ and skeletal muscle cell adhesion and proliferation $^{18}$.

Differentiation studies revealed no significant differences between the measured cell characteristics for the PEDOT polymer samples, with plastic dish TCP supporting relatively low numbers of mean cell branching, the lowest number of neurites per cell, 
and the lowest percentage of differentiated cells. TCP did however support the highest rates of cell proliferation, and therefore the surface may be optimised for cell proliferation, rather than differentiation. The PEDOT materials may however have an important function in providing structure and modulating proliferation rather than maximising it. Lower material moduli has been shown to promote neuron growth ${ }^{38}$, however there was no correlation evident for the range of material moduli measured here.

PEDOT-ULV supported proliferation rates of PC12 cells at a level comparable to the TCP and Au mylar material controls, and supported differentiation parameters similar to the other PEDOT films. Ulvan is a novel dopant that has not previously been employed for OCP cytocompatibility or electrical stimulation studies, while DBSA has previously been widely studied as a dopant for PPy in biocompatibility and electrical stimulation studies ${ }^{4,36,37}$. As such, PEDOT-DBSA and PEDOT-ULV were chosen for further investigation as cell supportive, redox active materials for the delivery of electrical stimulation to neural cells.

Electrical stimulation parameters were used in accordance with previously published methods due to their success in increasing neural cell differentiation ${ }^{4,33}$. The unstimulated PEDOT-DBSA controls supported a significantly increased mean cell body area, but had a significantly lower maximum neurite length per cell and lower number of mean neurites per cell than the unstimulated PEDOT-ULV films. Electrically stimulated PC-12 cells exhibited a significant increase in neurite length, branching, cell body area and number of neurites per cell compared to unstimulated PEDOT-DBSA, PEDOT-ULV and TCP controls. Previously electrical stimulation alone has been shown to enhance neural cell neurite outgrowth ${ }^{4,39}$ and the degree of differentiation ${ }^{40}$, with other studies finding the use of electrical stimulation in concert with growth factors presented beneficial neural cell development and differentiation ${ }^{6,33}$. Thus far most electrical stimulation studies have been undertaken either on metals or metal oxides ${ }^{40-42}$, or conducting polymers doped with synthetic dopants (i.e. polystyrene sulphonate, pts,

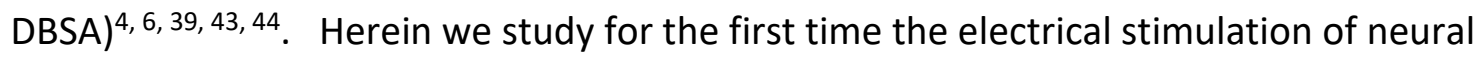


cells on a biologically doped conducting polymer, using the new algal derived dopant ulvan. As discussed previously, Ulvan is a biomedically relevant compound, presenting a similar molecular structure to heparin and illustrated to possess anticoagulant and antibacterial properties, and to be cytocompatible with osteoblast cells. ${ }^{24-26}$. The biofunctional benefits of Ulvan are coupled with it being sourced from algal- rather than animal-sources, removing ethical issues associated with obtaining the materials. Both PEDOT films were suitably stable over the period of stimulation, with PEDOT-DBSA proving to be superior to PEDOT-ULV as a material for the electrical stimulation of cells. Stimulated PEDOT-DBSA supported significantly increased maximum neurite length, mean branching per cell, mean cell body, mean neurite length per cell, mean neurites per cell and total outgrowth length per cell, compared to stimulated PEDOT-ULV. The significant increase in cell body area on the stimulated vs non-stimulated polymers could correlate with cell health, with increased cell body area in cortical pyramidal neurons previously correlated to healthy, rather than diseased, cells $s^{45,46}$.

Comparing the percentage of differentiated cells to undifferentiated cells, stimulated PEDOT-DBSA supported an increase in differentiated cells by $6 \%$ compared to unstimulated PEDOT-DBSA, while PEDOT-ULV demonstrated a much smaller increase of $2 \%$ (Figure 10). Cell differentiation rates were higher here compared to previous experiments (Figure 8) due to the use of laminin on the surface, thus increasing cell adhesion and clearly supporting cell differentiation. Thompson et al. ${ }^{6}$ and Stewart et al. ${ }^{4}$ used the same parameters as this study for the stimulation of cells for $1 \mathrm{~h}$ and $8 \mathrm{~h}$, respectively, while Kimura et al. ${ }^{40}$ used $100 \mathrm{~Hz}$ instead of $250 \mathrm{~Hz}$. Potential alterations of stimulation parameters to further enhance effects observed in neural cells include the altering of the frequency and amplitude of stimulation to observe its affects and also a shortened stimulation time period to determine its effect on neural differentiation.

\section{Summary and Conclusions}


Here we report on the cytocompatibility of PEDOT organic conducting polymers doped with synthetic and biologically derived dopants. Mechanical properties, as well as protein adsorption characteristics and cell proliferation and differentiation were investigated. We show that the new algal derived dopant ulvan is a suitable molecule for the doping of PEDOT films, showing appropriate biocompatibility and electrochemical properties. Electrical stimulation of PC-12 cells on PEDOT-DBSA and PEDOT-ULV has shown that this significantly enhances cell differentiation, demonstrating the viability of using large naturally occurring polysaccharide molecules as dopants in PEDOT biomaterials for cell and tissue electrical stimulation. Future work should be aimed at studying the modulation of dopant loading in the polymer on electrochemical and biointerfacing properties, and identifying the fundamental molecular mechanisms underlying the observed enhancement in cell differentiation.

\section{Acknowledgements}

The authors gratefully acknowledge funding from the Australian Research Council (ARC) through the Australian Centre of Excellence for Electromaterials Science (CE140100012). GGW is also grateful to the ARC for support under the Australian Laureate Fellowship scheme (FL110100196). We also thank the Australian National Fabrication Facility for access to equipment.

\section{References}

1. R. Muller, Z. Yue, S. Ahmadi, W. Ng, W. M. Grosse, M. J. Cook, G. G. Wallace and S. E. Moulton, Sensors Actuators B: Chem., 2016, 236, 732-740.

2. B. Zhang, P. J. Molino, A. R. Harris, Z. Yue, S. E. Moulton and G. G. Wallace, Journal of Materials Chemistry B, 2016, 4, 2570-2577.

3. K. Svennersten, M. Berggren, A. Richter-Dahlfors and E. W. H. Jager, Lab on a Chip, 2011, 11, 3287-3293.

4. E. Stewart, N. R. Kobayashi, M. J. Higgins, A. F. Quigley, S. Jamali, S. E. Moulton, R. M. Kapsa, G. G. Wallace and J. M. Crook, Tissue Engineering Part C: Methods, 2014, 21, 385393.

5. C. E. Schmidt, V. R. Shastri, J. P. Vacanti and R. Langer, Proceedings of the National Academy of Sciences, 1997, 94, 8948-8953.

6. B. C. Thompson, R. T. Richardson, S. E. Moulton, A. J. Evans, S. O'Leary, G. M. Clark and G. G. Wallace, J. Controlled Release, 2010, 141, 161-167. 
7. P. J. Molino and G. G. Wallace, APL Materials, 2015, 3, 014913.

8. A. R. Harris and G. G. Wallace, Adv. Funct. Mater., 2017, In Press.

9. P. J. Molino, A. Tibbens, R. M. I. Kapsa and G. G. Wallace, MRS Proceedings, 2013, 1569, 225-230.

10. J. Che, Y. Xiao, X. Zhu and X. Sun, Polym. Int., 2008, 57, 750-755.

11. A. R. Harris, S. J. Morgan, J. Chen, R. M. I. Kapsa, G. G. Wallace and A. G. Paolini, Journal of Neural Engineering, 2013, 10, 016004.

12. P. J. Molino, Z. Yue, B. Zhang, A. Tibbens, X. Liu, R. M. I. Kapsa, M. J. Higgins and G. G. Wallace, Advanced Materials Interfaces, 2014, 1, 1300122-n/a.

13. P. Gkoupidenis, N. Schaefer, B. Garlan and G. G. Malliaras, Adv. Mater., 2015, 27, 71767180.

14. R. A. Green, R. T. Hassarati, L. Bouchinet, C. S. Lee, G. L. M. Cheong, J. F. Yu, C. W. Dodds, G. J. Suaning, L. A. Poole-Warren and N. H. Lovell, Biomaterials, 2012, 33, 5875-5886.

15. M. H. Bolin, K. Svennersten, X. Wang, I. S. Chronakis, A. Richter-Dahlfors, E. W. H. Jager and M. Berggren, Sensors Actuators B: Chem., 2009, 142, 451-456.

16. P. J. Molino, M. J. Higgins, P. C. Innis, R. M. I. Kapsa and G. G. Wallace, Langmuir, 2012, 28, 8433-8445.

17. P. J. Molino, P. C. Innis, M. J. Higgins, R. M. I. Kapsa and G. G. Wallace, Synth. Met., 2015, 200, 40-47.

18. K. J. Gilmore, M. Kita, Y. Han, A. Gelmi, M. J. Higgins, S. E. Moulton, G. M. Clark, R. Kapsa and G. G. Wallace, Biomaterials, 2009, 30, 5292-5304.

19. F. J. Barkalow and J. E. Schwarzbauer, J. Biol. Chem., 1994, 269, 3957-3962.

20. F. Ronca, L. Palmieri, P. Panicucci and G. Ronca, Osteoarthritis Cartilage, 1998, 6, 14-21.

21. M. Hall and C. Ricketts, J. Clin. Pathol., 1952, 5, 366-366.

22. M. Baba, R. Pauwels, J. Balzarini, J. Arnout, J. Desmyter and E. De Clercq, Proceedings of the National Academy of Sciences, 1988, 85, 6132-6136.

23. J. Sun and H. Tan, Materials, 2013, 6, 1285.

24. W. Mao, X. Zang, Y. Li and H. Zhang, J. Appl. Phycol., 2006, 18, 9-14.

25. V. Gadenne, L. Lebrun, T. Jouenne and P. Thebault, Colloids Surf. B. Biointerfaces, 2013, 112, 229-236.

26. G. Toskas, S. Heinemann, C. Heinemann, C. Cherif, R.-D. Hund, V. Roussis and T. Hanke, Carbohydr. Polym., 2012, 89, 997-1002.

27. W. R. Otto, in Epidermal Cells: Methods and Protocols, ed. K. Turksen, Humana Press, Totowa, NJ, 2005, DOI: 10.1385/1-59259-830-7:251, pp. 251-262.

28. V. Castagnola, C. Bayon, E. Descamps and C. Bergaud, Synth. Met., 2014, 189, 7-16.

29. B. Paczosa-Bator, J. Peltonen, J. Bobacka and A. Lewenstam, Anal. Chim. Acta, 2006, 555, 118-127.

30. A. R. Harris, P. J. Molino, R. M. I. Kapsa, G. M. Clark, A. G. Paolini and G. G. Wallace, Synth. Met., 2016, 220, 394-401.

31. A. R. Harris, P. J. Molino, A. G. Paolini and G. G. Wallace, Electrochim. Acta, 2016, 197, 99-106.

32. J. Halper and M. Kjaer, in Progress in Heritable Soft Connective Tissue Diseases, ed. J. Halper, Springer Netherlands, Dordrecht, 2014, DOI: 10.1007/978-94-007-7893-1_3, pp. 31-47.

33. R. T. Richardson, B. Thompson, S. Moulton, C. Newbold, M. G. Lum, A. Cameron, G. Wallace, R. Kapsa, G. Clark and S. O'Leary, Biomaterials, 2007, 28, 513-523.

34. C. J. Wilson, R. E. Clegg, D. I. Leavesley and M. J. Pearcy, Tissue Eng., 2005, 11, 1-18.

35. R. A. Green, N. H. Lovell and L. A. Poole-Warren, Acta Biomater., 2010, 6, 63-71. 
36. B. C. Thompson, S. E. Moulton, R. T. Richardson and G. G. Wallace, Biomaterials, 2011, 32, 3822-3831.

37. A. Fahlgren, C. Bratengeier, A. Gelmi, C. M. Semeins, J. Klein-Nulend, E. W. Jager and A. D. Bakker, PLoS One, 2015, 10, e0134023.

38. L. A. Flanagan, Y.-E. Ju, B. Marg, M. Osterfield and P. A. Janmey, Neuroreport, 2002, 13, 2411.

39. J. E. Collazos-Castro, J. L. Polo, G. R. Hernandez-Labrado, V. Padial-Canete and C. GarciaRama, Biomaterials, 2010, 31, 9244-9255.

40. K. Kimura, Y. Yanagida, T. Haruyama, E. Kobatake and M. Aizawa, Med. Biol. Eng. Comput., 1998, 36, 493-498.

41. C. Sekirnjak, P. Hottowy, A. Sher, W. Dabrowski, A. Litke and E. Chichilnisky, J. Neurophysiol., 2006, 95, 3311-3327.

42. R. J. Jensen and J. F. Rizzo III, Journal of Neural Engineering, 2007, 4, S1.

43. F. Pires, Q. Ferreira, C. A. Rodrigues, J. Morgado and F. C. Ferreira, Biochimica et Biophysica Acta (BBA)-General Subjects, 2015, 1850, 1158-1168.

44. A. F. Quigley, J. M. Razal, B. C. Thompson, S. E. Moulton, M. Kita, E. L. Kennedy, G. M. Clark, G. G. Wallace and R. M. I. Kapsa, Adv. Mater., 2009, 21, 4393-4397.

45. G. Rajkowska, L. D. Selemon and P. S. Goldman-Rakic, Arch. Gen. Psychiatry, 1998, 55, 215-224.

46. L. A. Glantz, J. H. Gilmore, J. A. Lieberman and L. F. Jarskog, Schizophr. Res., 2006, 81, 4763. 